\title{
REACH: Better Knowledge and Better Use of Chemicals in the European Union\#
}

\author{
Cristina de Avila* and Eva C. Sandberg
}

\begin{abstract}
REACH is the proposed new chemicals regulation in the European Union. It builds on existing legislation, parts of which have been operating for 40 years, while tackling the identified shortcomings of the current system. The main objective of REACH is to improve the knowledge on chemicals, their properties and uses. In order to achieve this objective it is essential that industry assumes its responsibility to hold the knowledge on the substances they are manufacturing or importing and to share this knowledge with the authorities and their downstream users. $\mathrm{REACH}$ will require all substances manufactured and imported at and above one tonne per year to be registered. Through the Registration procedure, the obligation of industry to hold and share with authorities their knowledge of chemicals will materialise. REACH aims also to control better the use of substances of very high concern, this obviously includes the restriction of certain substances or certain uses. Through the Authorisation procedure, REACH will allow controlled use of substances of very high concern, such as carcinogens, mutagens and reprotoxic substances, substances that are persistent, bioaccumulative and toxic, and substances that are very persistent and very bioaccumulative. Increased knowledge and increased control, supplemented by substitution of dangerous substances and the fostering of innovation, will have as clear results a higher level of protection of human health and the environment, but additionally will bring along the opportunity to rebuild confidence in chemicals.
\end{abstract}

Keywords: Chemicals · European legislation · REACH

\section{Introduction}

The Chemicals legislation within the European Union has developed over more than 40 years and consists today of number of legal acts that covers both specific sectors such as workers' protection legislation, emissions of chemicals into the environment and those that are more horizontal.

There are four main horizontal instruments governing chemicals in the European

\footnotetext{
${ }^{*}$ Correspondence: C. de Avila

European Commission

Directorate-General for Environment

Chemicals Unit

BE-1049 Brussels

Tel.: +3222962545

Fax: +32 22966995

E-Mail: cristina.de-avila@ec.europa.eu
}

"Disclaimer 1: The views expressed are purely those of the authors and may not in any circumstances be regarded as stating an official position of the European Commission.

\#Disclaimer 2: This article draws up the main provisions of REACH, but it should not be taken as a full description of $\mathrm{REACH}$ and to fulfil the obligation it is necessary to follow the legal text.
Union today. These are Directive 67/548/ EEC on classification, packaging and labelling of dangerous substances [1], Directive 1999/45/EC on classification, packaging and labelling of dangerous preparations [2], Regulation (EEC) No. 793/93 on the evaluation and control of existing chemical substances [3] and Directive 76/769/EEC on the restrictions of marketing and use of chemical substances [4]. All these instruments are based on Article 95 of the EC Treaty [5] and therefore have the joint aims of preserving the internal market and assuring a high level of protection of human beings and the environment. Such a combined objective has been common since the outset of Community environmental legislation.

Regulation (EEC) No. 793/93 on the evaluation and control of existing chemical substances states that it is necessary to carry out a systematic evaluation of the risks from existing substances in order to protect human health and the environment. The work to do so is based on four priority lists containing all together 141 high production volume substances. It became, however soon clear that this was a very resource and time consuming process and, to date, risk assessments and risk reduction strategies have only been concluded for approximately half the number of these substances. Moreover, the process to intro- duce restrictions for substances posing an unacceptable risk to human health or the environment has also proven to be very slow and the burden of proof always rests on the authorities.

While Directive 67/548/EEC on classification, packaging and labelling of dangerous substances [6] stipulates that new chemicals have to be tested before they are placed on the market, there are no such provisions for 'existing' [7] chemicals. This 'unequal' treatment of new and existing chemicals has thus not been able to deliver relevant information on the main part of the chemicals on the market, but also hampered research and innovation, causing the EU chemicals industry to lag behind its counterparts in other parts of the world in this regard. It was these concerns, amongst others, identified in the Commission's review in 1998 [8], which led to the calls for a new chemicals strategy.

In their White Paper on the Strategy for a Future Chemicals Policy, published in February 2001 (COM (2001) 88) [9], the Commission outlined the result of a review of the current system and its new strategy for ensuring a high level of chemicals safety and a competitive chemicals industry through a system for the Registration, Evaluation and Authorisation of Chemicals - REACH. 
The White Paper identified seven objectives that need to be balanced within the overall framework of sustainable development:

- Protection of human health and the environment;

- Maintenance and enhancement of the competitiveness of the EU chemical industry;

- Prevention of fragmentation of the internal market;

- Increased transparency;

- Integration with international efforts;

- Promotion of non-animal testing;

- Conformity with EU international obligations under the WTO.

One of the main goals of the new system is to create a legislation that has the same requirements for all chemicals that are manufactured or imported to the European Union, i.e. the 'unequal' treatment of new and existing chemicals should be removed. Another important goal is that the burden of proof has to be shifted from the authorities to industry. This means that industry has to show that the substances they manufacture, import or place on the market can be used in a 'safe' way.

\section{Better Knowledge}

\section{The Registration Phase in REACH}

One of the main objectives of the REACH Proposal is to make industry responsible for providing the necessary information to assess the risks linked to the use of chemicals. To achieve this aim, REACH establishes the obligation for companies to 'register' the substances they manufacture or import into the European Union. Registrations are obligatory for substances manufactured and imported above one tonne per manufacturer/importer per year $(\mathrm{t} / \mathrm{y})$.

The registration procedure is inspired by the principle of proportionality and hence prioritises those substances that pose highest risks to man and the environment. The first prioritisation effort is done by reducing the scope not only of the Regulation itself but also of Registration system [10].

Exemptions to Registration are provided for those substances that are already regulated in specific community legislation (for example, to the extent that substances are used as active ingredients for biocides or plant protection products they do not have to be registered, nor is there the need to register substances that had already been notified under the current notification system for new substances) or substances for which the hazards are well-known to be low (case of the substances listed in Annex IV to the REACH Regulation). Other exemptions to registration are listed in Annex V to the REACH Regulation and include, under given circumstances, substances that result from a chemical reaction and are not themselves manufactured, imported or placed on the market, by-products that are not imported or placed on the market, naturally occurring substances under certain conditions, etc.

A second prioritisation effort is to require that some of the most hazardous substances, such as those which cause cancer, mutations or are toxic to reproduction, are registered first. The same applies to substances that are very toxic to aquatic organisms or may cause long-term adverse effects in the aquatic environment. These substances will have to be registered within a short deadline (i.e. three years after entry into force).

Prioritisation is further achieved through the application in the provisions of the Regulation of the criteria of exposure, and its most commonly used proxy: tonnage.

Registrations will have to be submitted to the new European Chemicals Agency in a staggered manner on the basis of the manufacturing/import tonnage. While newly developed substances (also known as "non phase-in substances') have to be registered before being placed on the market, in the case of the so-called phase-in substances (those listed on EINECS or those manufactured but not placed on the market at least 15 years before the entry into force of REACH) the deadlines for submissions will vary. A company that manufactures/imports a substance above $1,000 \mathrm{t} / \mathrm{y}$ will have to submit a registration dossier within three years of the entry into force of the REACH Regulation, while a company manufacturing/importing a substance in between one and ten tonnes will only have to register it eleven years after the Regulation's entry into force.

However, prioritisation on the basis of tonnage is achieved not only through longer deadlines for the submission of registrations for phase-in substances, but also through the amount of information comprised in the registration dossier. Consequently, a dossier for a phase-in substance manufactured or imported between one and ten tonnes and which does not meet the screening criteria set in the Regulation, will only consist of physicochemical properties of the substances; however, a dossier for a phase-in substance manufactured or imported above 1,000 tonnes will have to contain information not only on the physicochemical properties of the substances, but also abundant information on its toxicity and eco-toxicity.

A key element of the registration dossier is the Chemical Safety Report (CSR) which documents the Chemical Safety Assessment (CSA) of the substance. The registrant has to perform a CSA for registrations of substances manufactured or imported above $10 \mathrm{t} / \mathrm{y}$ to assess the hazards and classification of substances, and look into whether the substance is persistent, bioaccumulative and toxic (PBT) or very persistent and very bioaccumulative (vPvB). For uses of substances classified as dangerous or for those which are PBTs or vPvBs, exposure scenarios will have to be included in the assessment in order to describe how substances are manufactured or used during their life-cycle and how the manufacturer or importer controls, or recommends to control, exposures of human beings and the environment.

A crucial part of exposure scenarios is the inclusion of risk management measures which aim at ensuring an adequate control of the risks derived from the uses of the substance. Exposure scenarios determine the so-called 'identified uses' of the substance registered. Identified uses are those covered in the CSA and should include the own uses of the manufacturer or the importer, as well as those uses communicated by his downstream users. The exposure scenarios will be annexed to the safety data sheets that accompany the supply of a substance to downstream users and further distributors.

The prioritisation system through staggered deadlines and information levels, as decided by the Council in its Common Position, is summarised in the Table.

\section{Information Down the Supply Chain}

The aim of the Registration procedure under REACH is two-fold. On the one hand, there is an urgent need to increase the information levels on chemicals, both from an institutional but mostly from a practical, industrial point of view, in order to ensure that all relevant parties have sufficient information on the substances used. On the other hand, the information collected by manufacturers and importers in order to complete a registration dossier, will have to be used in order to set and recommend risk management measures throughout the supply chain. Different 'chemical scandals' that have emerged in the European Union in the last decades have shown industry either holding insufficient information on their substances or an unacceptable lack of communication on the properties and risks associated with the use of substances down the supply chain.

In order to illustrate how the REACH Registration procedure will perform in terms of information down the supply chain, and the improvements it will bring to the current system, we can use the example of the so-called 'Ardystil case'.

Ardystil was a company undertaking design printing in the textile sector in region of Valencia, Spain. The product used for the fabric printing was Acramin F, created and marketed by Bayer for roller application and supplied by Bayer in powder form. When the supply of Acramin F in powder form was replaced by the liquid form, Ardystil started spray-painting the textiles. Health disorders amongst Ardystil work- 
Table. Registration deadlines and information requirements under the Council Common Position on $\mathrm{REACH}$

\begin{tabular}{|c|c|c|}
\hline Substances & Information Requirements & Timing \\
\hline $1-10$ tonnes & $\begin{array}{l}\text { Non phase-in substances: Full Annex } \\
\text { VII } \\
\text { Phase-in substances: } \\
\text { - Physico-chemical properties of Annex } \\
\text { VII } \\
\text { - If prioritised through criteria set in } \\
\text { Annex Ic: Full Annex VII }\end{array}$ & $\begin{array}{l}\text { Before marketing: non phase-in } \\
\text { Phase-in } \\
3 \text { years: CMR (cat } 1 \text { and } 2 \text { ) > } 1 \text { tonne } \\
11 \text { years: Phase-in substances }\end{array}$ \\
\hline $\begin{array}{l}10-100 \\
\text { tonnes }\end{array}$ & $\begin{array}{l}\text { Phase-in and non phase-in } \\
\text { substances: } \\
\text { - Information in Annexes VII and VIII } \\
\text { - Chemical Safety Report (CSR) }\end{array}$ & $\begin{array}{l}\text { Before marketing: non phase-in } \\
\text { Phase-in: } \\
3 \text { years: CMR (cat } 1 \text { and } 2 \text { ) > } 1 \text { tonne } \\
11 \text { years: rest of phase-in } \\
\text { substances }\end{array}$ \\
\hline $\begin{array}{l}100-1000 \\
\text { tonnes }\end{array}$ & $\begin{array}{l}\text { Phase-in and non phase-in } \\
\text { substances: } \\
\text { - Information in Annex VII and VIII } \\
\text { - Testing proposals for tests required in } \\
\text { Annex IX } \\
\text { - CSR }\end{array}$ & $\begin{array}{l}\text { Before marketing: non phase-in } \\
\text { Phase-in } \\
3 \text { years: } \\
\text { - CMR (cat } 1 \text { and } 2 \text { ) > } 1 \text { tonne } \\
\text { - R50/53 substances (very toxic to } \\
\text { aquatic environment) > } 100 \text { tonnes } \\
6 \text { years: rest of phase-in substances }\end{array}$ \\
\hline $\begin{array}{l}>1000 \\
\text { tonnes } \\
+\mathrm{CMR}\end{array}$ & $\begin{array}{l}\text { Phase-in and non phase-in } \\
\text { substances: } \\
\text { - Information in Annex VII and VIII } \\
\text { - Testing proposals for tests required in } \\
\text { Annex IX and X } \\
\text { - CSR }\end{array}$ & $\begin{array}{l}\text { Before marketing: non phase-in } \\
\text { Phase-in } \\
3 \text { years: } \\
\text { - CMR (cat } 1 \text { and } 2 \text { ) > } 1 \text { tonne } \\
\text { - R50/53 substances (very toxic to } \\
\text { aquatic environment) > } 100 \text { tonnes } \\
\text { - rest of phase-in substances }\end{array}$ \\
\hline
\end{tabular}

ers commenced when they were exposed to Acramin $\mathrm{F}$ by inhalation. As a consequence of this change in the application and hence the exposure to Acramin F, six workers contracted a mysterious lung disease and died; 72 other workers employed by Ardystil and other textile printing companies contracted a serious pulmonary disease (at the time called 'Ardystil syndrome', now identified as Bronchiolitis Obliterans Organizing Pneumonia - BOOP).

Had REACH been in place in 1992, when the case arose, things could have been different. The information that will be generated with REACH Registration and the knowledge that will be sent or forwarded down the supply chain will be a key element for a better performance of legislation in the workplace. To start with, Bayer would have either registered the substances contained in Acramin $\mathrm{F}$ for the purposes of using it in this particular application (if it manufactured the substance(s)) or would have received the relevant information from its suppliers who would have registered the substance(s), if Bayer had not been the manufacturer but a downstream user. In the registration dossiers, information would have been available on the toxic properties wise, downstream users do not have the obligation to register themselves, and benefit from their suppliers' registrations, provided that the way in which the substance is used falls within the exposure scenarios and the identified uses. Downstream users might also choose not to inform their suppliers of the uses given to the substances, opting to do the CSA themselves.

In REACH, Safety Data Sheets (SDS) continue to be the primary tool for information of information on a substance down the supply chain. The provisions of the current SDS Directive (91/155/EEC) [11] are carried over into the REACH Regulation with the addition of the need to provide them for substances (and preparations containing substances) that are PBT or $\mathrm{P}$ PB. It is only to be expected that the quality of information contained in the SDS will improve, given that more information will have to be collected or generated for the purposes of registration.

\section{Better Knowledge and Better Appli- cation of Existing Legislation}

We have illustrated above how $\mathrm{REACH}$ will not only improve the current knowledge and risk management of chemicals in the European Union, but how it will also lead to a better application of existing legislation, such as legislation on occupational health and safety.

Today there is a strong link between the main pieces of chemicals legislation and other environment legislation. The EC Chemicals legislation is key in providing the necessary risk assessment to support policy measures in other sectors: when an identified risk needs to be controlled, measures can be taken either through a restrictions in the directive on the Limitations of Marketing and Use Directive (Directive $76 / 769 / \mathrm{EEC}$ ) or through the adoption of measures under other legislation (such as emission limits to water or air; restrictions in the use in specific products, for example on vehicles or on electric and electronic equipment; due to the performance of these substance when the products become waste, or even the rules existing for granting permits under the Integrated Pollution and Prevention Control Directive [12], etc.).

All this is not only relevant in the case of other Community environmental legislation, but is also applicable to other areas, for example to legislation on occupational health and safety, as well as to other product-related legislation.

As is the case with current legislation, the relationship between REACH and other legislation is complementary, following an in-depth analysis to avoid all possible overlaps. The increased knowledge on the properties of substances that REACH will bring will be of use in all the other policy areas mentioned above for a better performance of legislation. 


\section{Better Use}

\section{Controlling the Use of the Most Dangerous Chemicals - Authorisa- tion or Restrictions?}

As we have seen above, under the REACH Regulation, industry will have to take full responsibility for the use and the necessary risk management measures for most substances they manufacture, import and use. However, the most dangerous substances have hazardous properties of such a high concern that it is essential to regulate them centrally, at Community level, through a mechanism that ensures that the risks related to their actual uses are assessed and that the appropriate risk reduction measures are the same in all EU Member States. This is justified because the effects of these substances on human beings and the environment are very serious and normally irreversible. For example, once a very bioaccumulative and very persistent substance appears in the environment it is impossible or next to impossible to get rid of it and if emissions, albeit very small, continue the concentrations in the environment will increase over time and earlier unknown effects might become evident.

REACH foresees two ways of preventing or limiting the risks from this group of substances. First, through the Restrictions procedure substances that pose unacceptable risks can be completely banned or their uses restricted. The burden of proof that such a restriction is necessary will remain with the authorities. Second, the Authorisation procedure will ensure that the risks from substances of very high concern (SVHC) are adequately controlled. Such a control will have to be proved by industry through an authorisation application and subsequent granting of the authorisation by the authorities. An authorisation may also be granted if the socio-economic benefits outweigh the risks from the use of the substance.

REACH defines the substances of very high concern as those that meet the criteria for carcinogenic, mutagenic or toxic for reproduction (CMRs) category 1 or 2 ; those that are persistent, bioaccumulative and toxic or very persistent and very bioaccumulative (PBTs/vPvBs); or those identified as causing serious effects to human beings or the environment equivalent to those above on a case-by-case basis, such as endocrine disrupters.

Among the group of existing substances ('phase-in' substances) it is roughly estimated that about 1,500 substances will meet the criteria for authorisation. However, it will not be possible to carry out the process for all these substances at the same time and immediately when REACH enters into force. A prioritisation process, deciding which substances require authorisation earliest, has therefore been included in the authorisation procedure and it will be not until a decision has been taken to prioritise a specific substance that its uses will have to be authorised. It will then be included in a special annex (Annex XIV). The annex will specify the last date for application for an authorisation for a specific use and also the date after which the substance cannot be used anymore (the sunset date) unless an authorisation has been granted or the user has applied for an authorisation but a decision is not yet taken. In general priority should be given to substances with:

- PBT or vPvB properties;

- wide dispersive use, or

- high tonnages.

In the consideration of REACH in the European Parliament and the Council (the body which represents the governments of the Member States) both these two colegislators added an extra procedural step before the inclusion of a substance on Annex XIV. This step is called 'the Candidate list' by the Council but the European Parliament split the annex into two parts, a) and b). Such a list would contain all substances that meet the criteria for substances subject to authorisation and these substances are to be put on the list a short time after they have been identified as a substance potentially subject to authorisation. This is seen as early information to companies placing on the market or using such substances, but does in itself not pose any obligations on any stakeholder.

The process for including a substance on the candidate list is quite transparent and a proposal needs to be justified through an annex XV dossier, and will also be published on the Agency website - allowing comments from stakeholders - before a decision is taken to include it on the candidate list.

For inclusion in Annex XIV, that is when the deadlines are set for applying for an authorisation and the sunset date is given, the decision will be taken through Comitology [13] but before that the recommendation from the Agency will have to be published on its website. It is also possible for the Commission to exempt certain uses of a substance from the authorisation if sufficient controls to protect health and the environment are already established under other Community legislation.

The authorisation itself is requested by industry and granted by the Commission for a given use to a manufacturer, importer or a downstream user of the substance. Downstream users can benefit from the authorisation granted to the supplier for a specific use, as long as the substance is used in accordance with the conditions given in the authorisation. It will also be possible for a group of companies, suppliers and/or downstream users to apply for an authori- sation together with other users and/or for several substances whose physicochemical, toxicological and ecotoxicological properties are likely to be similar.

An authorisation for a use of a substance will be granted if the risks from the use of the substances arising from the intrinsic properties making it subject to authorisation are adequately controlled. By adequate control is meant that the estimated exposure levels do not exceed the appropriate DNEL or PNEC [14] and that the likelihood and severity of an event occurring due to the physicochemical properties of the substance is determined as negligible in the CSA by the applicant.

How to derive these values and how to otherwise conclude what adequate control means is defined in Annex I to REACH. When applying for an authorisation it is always obligatory to include in the application an analysis of the alternatives - other less dangerous substances or other technologies - considering their risks and the technical and economic feasibility of substitution.

If an authorisation cannot be granted because it is not possible to adequately control the use of the substance, a use may still be authorised if the socio-economic benefits outweigh the risks to human health and the environment arising from the use of the substance, and if there are no suitable alternative substances or technologies available. In this context it has been much discussed if substances for which it is not possible to set a DNEL or PNEC, e.g. a non-threshold carcinogen or a $\mathrm{vPvB}$ can ever be considered to be adequately controlled.

In its first reading the European Parliament has adopted stronger requirements on authorisation than the Council and specifically they would require that if a less dangerous alternative is available, substitution for that should always take place (mandatory substitution). The European Parliament also set a time-limit of five years for any authorisation but the authorisation might be renewed if a new application is submitted.

The Council, meanwhile, has not favoured a fixed time-limit for authorisations but required that they are subject to a timelimited review set on a case-by-case basis. The issue of to what extent substitution should be mandatory and when to require and how to set a time-limit, is likely to be one of the main issues for which a compromise has to be found between the European Parliament and the Council if a second reading agreement should be feasible.

\section{How Should Control Substances be Controlled when Contained in Articles?}

The importance of exposure to chemicals via their presence in articles and the consecutive diffuse dissemination has been increasingly discussed over the last decade. 
It was therefore considered important that REACH also included provision for these cases. However, as many millions of articles are produced in or imported to the European Union every year, it would not be realistic to require a registration of all substances used to produce or contained in articles. The key was to find a way to catch the cases where the presence and possible release of substances in articles could give rise to risks for health and environment. It was also important to find a way that did not discriminate either the European Union producers or the non-EU producers of articles and that was fully WTO-compatible.

In REACH there are two different types of provisions for substances in articles. The first one relates to the intended release of substances from articles, e.g. the toner used in a photo copier or printer. In this case all substances in the toner would have to be registered - and pre-registered - just as any other substance in a preparation and the registration follows the same time-line ( 3 , 6 or 11 years according to tonnage) and requirements as any other registration unless the substance has already been registered for that use when there is no obligation to register the substance.

For all other articles there is an obligation for any producer or importer of articles to notify the appropriate Agency that would be responsible for the specific substance contained in the article that meet the criteria for authorisation and that appear on the candidate list. The notification procedure is much lighter than a registration and only requires the notifier, i.e. the manufacturer or importer of an article, to supply the Agency with information in relation to the identity of himself and the substance, the classification of the substance and a brief description of use as well as the tonnage range of the substance. This obligation only applies if the substance is present in those articles at or above one tonne per producer or importer per year and if the substance is present in those articles above a concentration of $0.1 \%$ weight by weight (w/w).

However, the requirement to notify any of these substances will not apply where the producer or the importer can exclude exposure to humans or to the environment during normal and foreseeable conditions of use, including disposal.

Furthermore, there is no obligation to register or notify a substance if a registration has already been made by anyone for that substance and that use.

Following notification and in other instances where neither notification nor registration is requested, the Agency can require a registration of a substance if it has grounds to suspect that the substance is released from the articles, and the release of the substance from the articles presents a risk to human health or the environment.
The requirement for notifying these substances of very high concern present in articles will start to apply six months after the first registration deadline, which occurs three years after entry into force of REACH.

\section{Classification and Labelling: An Inventory for Consistent and Transparent Information}

Already in 1967, the first criteria were adopted on how to classify and label substances on the basis of their intrinsic properties. Since then criteria, which have been developed and amended over the years, have been used as a basis for creating harmonised classification and labelling of substances on a Community basis.

These harmonised classifications of substances are included in Annex I to Directive 67/548/EEC, which has, to date, been adapted 29 times and contains about 3,800 substances. However industry has also the obligation to use the criteria for the classification and labelling of any substances they place on the market even if there is no harmonised classification. Today, there is no structured follow-up of these classifications, consequently, a substance placed on the market by several different companies can thus have different classification and labelling depending on the supplier, his knowledge to classify and the available data he has and on which the classification is based.

To improve the current situation, REACH introduces an obligation for all companies that place a substance on the market to inform the Agency about the classification of that substance. The Agency will then gather all the classifications in an inventory, which will be published on its website. In the case that the same substance appears on the inventory with different classifications, the companies involved have to make all possible efforts to come to an agreement on how to classify that substance. The creation of the Inventory will contribute to making the information on the intrinsic hazardous properties more consistent and transparent as information will be easily available from the Inventory.

Harmonised classification will only be carried out as is stated in REACH for substances that are carcinogenic, mutagenic or toxic to reproduction category 1 and 2 or substances that are respiratory sensitizers. In addition to that, any Member State may propose that a substance having other dangerous properties than those mentioned above also will get a harmonised classification. This will have to be decided on a case-by-case basis.

Currently, the Commission is preparing a proposal for implementing the Globally Harmonised System (GHS) for the classification and labelling of chemicals into EU law. It is the intention that the requirements for using the criteria for substances in line with GHS should be applicable three years after entry into force of REACH as this is the date when the industry have to report the classification and labelling of all substances they place on the market to the European Chemicals Agency so it can put together the Inventory.

\section{The Implementation of REACH}

To some companies, the legal obligations required in a highly technical legal text could be difficult to grasp. This problem could even be more acute in the case of small and medium sized enterprises, (SMEs), as they may not be in the position to hire legal or toxicological technical assistance to comply with the legal requirements. It is therefore already practice for the Commission to issue technical guidance on how to apply complicated or very technical legislation. Such guidance is directed both to industry and to Competent Authorities in member states.

For REACH, the elaboration and development of clear guidance has been deemed perhaps even more necessary as many new technical requirements have been introduced into the legislation. Consequently guidance documents and IT-tools for industry and the authorities will be adopted by the new European Chemicals Agency, once it starts operating. In order to start covering the practical discussions for the development of these guidance documents, the Commission has set up a number of so-called REACH Implementation Projects (RIPs).

As a result, there is a RIP [15] that tries to clarify the different tasks and obligations for industry under REACH, but also answers many technical questions, such as how to interpret test results or how to carry out a Chemical Safety Assessment. Another RIP [16] aims at giving guidance to the competent authorities in the member states in terms of the various requirements under REACH, such as those applicable when they want to supply a proposal for a restriction, inclusion of a substance on the candidate list for authorisation or a harmonised classification and labelling.

The guidance documents are being elaborated in close contact with stakeholders. In some cases several stakeholders have formed a consortium and drafted the guidance which is then discussed in a stakeholder expert group (SEG). The European Chemicals Bureau, which is part of the Commission's Joint Research Centre, is the body coordinating all the RIPs and further information on the RIPs is available at the ECB website. It is also the intention that all the drafts for guidance will be available for comments via this website [17]. 


\section{Conclusions}

The proposed REACH Regulation is an ambitious piece of internal market legislation which has as main objective (beyond ensuring the free circulation of chemicals in the internal market) to generate knowledge on chemicals marketed in the European Union and control the risks derived from their use.

REACH places a shared responsibility of the system on industry and authorities (both at community and national levels), making sure that those that have the knowledge share it with those in charge of adopting risk management or reduction measures as well as with those using the substances.

One of the main achievements of REACH will be to tackle the "burden of the past': REACH will increase the knowledge on the properties of chemicals and how they are used. This increased knowledge will result in a better management of the risk associated with the use of chemicals. Better management in a wide sense, as the increased knowledge will not only allow for the application of appropriate risk reduction measures through the supply chain, but also will allow a better performance of existing sectoral legislation (such as that on occupational health and safety, product legislation, legislation on waste or on emissions).

Furthermore, the authorisation system catered for in REACH will call for the substitution of the most dangerous substances.

Increased knowledge and increased control, supplemented by substitution of dangerous substances and the fostering of innovation, will have as clear results a higher level of protection of human health and the environment, but additionally will bring along the opportunity to rebuild confidence in chemicals.
[1] OJ $16.8 .1967,196,1$. Directive as last amended by Commission Directive 2004/73/EC, OJ 30.4.2004, L 152, 1. Corrected in $O J 16.6 .2004, L 216,3$.

[2] $O J$ 30.7.1999, $L$ 200, 1. Directive as last amended by Commission Directive 2006/8/EC, OJ 24.1.2006, L 19, 12.

[3] $O J$ 5.4.1993, $L 84,1$. Regulation as amended by Regulation (EC) No $1882 / 2003$ of the European Parliament and of the Council, OJ 31.10.2003, L 284, 1.

[4] OJ 27.9.1976, $L 262,201$. Directive as last amended by Directive 2005/90/EC of the European Parliament and of the Council, OJ 4.2.2006, L 33, 28.

[5] OJ 24.12.2002, C 225, 33 .

[6] $O J 16.8 .1967,196,1$. Directive as last amended by Commission Directive 2004/73/EC, OJ 30.4.2004, L 152, 1. Corrected in $O J 16.6 .2004, L 216,3$.

[7] The distinction, introduced under regulation (EC) 793/93, between so-called 'existing' and 'new' chemicals is based on the cut-off date of 1981. All chemicals that were put on the market before 1981 are called 'existing' chemicals and they appear on the European Inventory for Existing Chemical Substances (EINECS). In 1981, they numbered more than 100,000 different substances. Chemicals introduced to the market after 1981 (more than 3800) are termed 'new' chemicals.

[8] SEC(1998)1986 final (1998) Report on the operation of Council Directive 67/548/ EEC of 27 June 1967 on the approximation of the laws, regulations and administrative provisions relating to the classification, packaging and labelling of dangerous substances, Council Directive 76/769/EEC of 27 July 1976 on the approximation of the laws, regulations and administrative provisions of the Member States relating to restrictions on the marketing and use of certain dangerous substances and preparations, Directive 1999/45/EC of the European Parliament and of the Council of 31
May 1999 concerning the approximation of the laws, regulations and administrative provisions of the Member States relating to the classification, packaging and labelling of dangerous preparations and Council Regulation (EEC) No 793/93 of 23 March 1993 on the evaluation and control of the risks of existing substances.

[9] European Commission, 'White Paper on the Strategy for a Future Chemicals Policy', COM 200188.

[10] The following are exempted from the REACH Regulation: radioactive substances; substances subject to customs supervision which are in transit, in temporary storage, or in a free zone or free warehouse with a view to re-exportation, and provided they do not undergo any treatment or processing; non-isolated intermediates; waste.

[11] Commission Directive 91/155/EEC of 5 March 1991 defining and laying down the detailed arrangements for the system of specific information relating to dangerous preparations in implementation of Article 10 of Directive 88/379/EEC, OJ 1991, $L$ $76 / 35$, as amended.

[12] Council Directive 96/61/EC of 24 September 1996 concerning integrated pollution prevention and control $O J 10.10 .1996, L$ 257.

[13] Comitology is the decision process where the Commission takes a decision after having discussed it with Member States representatives and been approved by a majority of the weighted votes.

[14] DNEL: Designated no effect level; PNEC: Predicted no effect concentration.

[15] RIP 3, consisting of ten subprojects.

[16] RIP 4, consisting of five subprojects.

[17] http://ecb.jrc.it/REACH/ 